\title{
The Content Study of Chinese College Sports Quality Education
}

\author{
Liane Duan ${ }^{1, a}$ \\ ${ }^{1}$ Faculty of Business, Wuhan Polytechnic, WuHan, China \\ a120804148@qq.com
}

\author{
Keywords:Chinese Universities, Physical Education, Quality Education, Teaching Mode
}

\begin{abstract}
Quality education has become the dominant idea of all kinds of education at all levels. How to full implementation of quality education in physical education teaching, become the primary task of the physical education teaching in colleges and universities as they are the basic qualities of modern talent cultivation base. This paper studies China's colleges and universities sports quality education content, in order to provide China's colleges and universities sports teaching quality and improve the physical quality of college students.
\end{abstract}

\section{Introduction}

From theory to practice and sports education vigorously investment, since Chinese university physical education reform has made remarkable achievements, to lay a good foundation for the development of college physical education, but these reforms range of form and content is relatively narrow, not from the point of view of society, economy, culture and education development to analyze the problems existing in the sports education, therefore cannot fundamentally solve the existing problems [1]. Nowadays China's rapid economic development, the progress of science and increasingly era, to grasp the evolvement of China's political, economic, university sports education values and the change of the value target, analyzes the present situation of China's university education, so that we can correctly grasp the trend of the development of the college physical education reform, gradually improve the quality of university physical education.

\section{The situation of foreign universities sports education}

Because of the American college of sports education lack of correct understanding of sports, cause the loss of the system and health level of students and the unbalanced development of body and mind. The former Soviet Union sports education under the influence of communism, lead to physical education concept is more rigid, finally when its population decline, reduced life expectancy, to arouse people's attention [1]. Currently, the concept of university physical education has been closely integrated with health, teaching content is rich, including physical exercise, mental health and system, accident prevention, etc. Russia's sports education will increase the number of physical education, the teaching content includes range is more extensive. Prior research on Chinese students physical quality investigation suggests that college students the basic physical quality obviously showed a trend of decline, the Chinese university students overall health continued to decline, shape, height, weight system indexes such as serious is not up to standard, and some decline in health indicators have reached the point of concern [2]. In addition, according to the world health organization recently published data about college students' mental health shows that college students suffer from compulsive habit disorder accounted for half of the total, China youth mortality is three times the elderly mortality [2]. So China, the reform of college sports is imminent, related personnel must find problems as soon as possible, solve the problem, in determining the "people-oriented, health first" guiding ideology, improve the quality of college physical education, promote the development of students' physical and mental health. 


\section{The existing problems in the college physical education}

College sports due to deep the influence of traditional ideas, in the process of implementing quality-oriented education, can not fully understand the connotation of sports education, aeriform in killing the specialty students some ways. In the university sports teaching platform, teachers and students plays a different role, that physical education is full of vitality, and in the current college sports teachers in a dominant position in the teaching, the teacher according to the curriculum to guide students to learn, because the content of the students don't like physical education(PE) class, tired of physical education classes, over time, in defiance of the teacher's leading role, excessive pursuit of that oneself like, let the teachers are in a passive state. These questions are not conducive to improvement of the university sports education, if not taken seriously, will cause the confusion of physical education in target execution [3]. The following mainly elaborated the university sports education for middle school students learn with defects, tutors have a deviation, the problem such as the curriculum of the single.

\section{The content of the university sports quality education}

Is a pattern in the process of teaching, teaching in colleges and universities sports teaching is no exception. In the process of teaching, as a college PE teachers, their own must first have a correct view of the world, must have a noble moral character and lofty spiritual realm. College sports teachers' moral quality of students, the most influential excellent college sports teachers to do a teacher by worthy example, civilization and manners, have the courage to correct mistakes [4]. Good qualities of college PE teachers can make students produce feeling admire feeling love and positive to imitate and produce positive effect; On the other hand, can bring negative or bad influence to students. Colleges and universities sports teaching both the university sports theory class and physical training.

Therefore, colleges and universities sports curriculum is the core of implementing quality education thought, let the student connotation of college sports culture quality, and have a certain ability of sports practice. As the foundation education of college sports and other disciplines, is shouldering the task of improving the quality of the ideological and moral cultivation and health.

Optimization of college physical education teaching mode, is implements the education for all-around development the main channel. The teaching of college sports quality education, optimize the classroom teaching mode is a key, is also a main channel of implementing quality-oriented education [4]. To realize optimization of college PE classroom teaching, however, this requires our physical education teachers in colleges and universities should be to optimize the university sports teaching goal formulation, optimize the design of the college PE classroom teaching, optimize the combination of university sports teaching methods, etc., by optimizing the college PE classroom teaching modes, in order to achieve the purpose of the implementation of quality education.

The optimization goal for colleges and universities sports teaching. Teaching goal is to build the key point of quality education, it requires that the college sports teachers must understand, familiar with and master the teaching content, clear the universities sports teaching outline, according to their aptitude, to make the goal of teaching. , to say the goal of teaching is to all colleges and universities sports teaching content into a specific goal, first of all do finish every class of small target, and then complete unit of a part of the target, so as to achieve the total goal [3]. Before physical education teachers in colleges and universities teaching new content, first of all, make clear the teaching aim of this course, the syllabus on the tip of the teaching steps, to analysis what is the difficulty of students attain the goal. Based, and according to the students' learning habits, learning methods and interests, drilled into colleges and universities sports teaching content, clear the universities sports teaching goals, determine the key and difficult point for each class, the university sports teaching goal in time to the students at the same time, let the student know, so as to achieve the teaching goals, learning goals, instruction inspection also have goals, make it can be targeted for sports teaching in class, complete set of colleges and universities sports teaching goal smoothly. 
The design optimization of college physical education classroom teaching. Colleges and universities sports teaching should make efforts to guide students from passive to accept knowledge, to take the initiative to explore knowledge, become "want me to learn" to "I want to learn". To do this have to cultivate the students' interest in learning, to let them take the initiative to participate in university sports teaching activities, to arouse the enthusiasm of their physical education learning and subjective initiative, forming students' thinking as the core, ability as the goal, the quality of education for the purpose of education teaching mode. In the optimization of college PE classroom teaching design, can use "heuristic", "learning guide type" teaching method [5]. First, college sports teachers should play a guiding role, do a simple, in order to achieve the goal of "guide" on the key. Second, before learning difficulties of students to study, when students have difficulty in learning, urgently needs the teacher out when answering questions, the teacher should guide in time, grasp the key moment, just right [5]. Of course, in addition to ready for extracurricular physical education teachers in colleges and universities should also elaborate design, analysis of what content to let the students self-study; What the teacher demonstrates, What with speaking practice form? The university sports teaching focus from "teaching" to "learning", to make the students become passive to active, truly become the main body of college sports teaching activities. It can cultivate students' interest in independent learning, inspire their desire of knowledge, enhance learning confidence and active learning the enthusiasm.

The combination of optimization of college physical education teaching methods. As the updating of teaching ideas, colleges and universities sports teaching methods must also change, which requires the further optimization of the combination of teaching methods [1]. What teaching methods of college PE teachers in class, students tend to adopt the corresponding learning methods, it directly affects the student's learning effect. Therefore, in classroom teaching of college PE teachers should try to have a flexible and varied teaching methods, carefully designed each link in the process of sports teaching in colleges and universities, around the development of students' health quality of teaching.

Build quality education teaching mode, the key lies in college physical education teachers' own quality. Is a pattern in the process of teaching, teaching in colleges and universities sports teaching is no exception. In the process of teaching, as a college PE teachers, their own must first have a correct view of the world, must have a noble moral character and lofty spiritual realm [6]. College sports teachers' moral quality of students, the most influential excellent college sports teachers to do a teacher by worthy example, civilization and manners, have the courage to correct mistakes. Good qualities of college PE teachers can make students produce feeling admire feeling love and positive to imitate and produce positive effect; On the other hand, can bring negative or bad influence to students [6]. Colleges and universities sports teaching both the university sports theory class and physical training. Therefore, college physical education teachers is both knowledge workers and manual laborers. Apart from the heavy teaching task, to take a lot of after school training, contest and the referee work. Therefore, as a college PE teachers should be loyal to education career and love their job, with noble moral character and bear hardships and stand hard work, dedication, can we truly achieve the teaching.

Patient enlighten education, cultivate interest. In the sports teaching, the teacher must through magny cours, xiao zhi Daniel, causes the student to understand "virtue, intelligence are sent in body". Only the all-round development of morality, intelligence and physique, to become qualified personnel; Only get the strong body, can energetically into heavy study; Only play good body, can adapt to the fierce competition in the society, to better service to the nation [7]. Once students made clear the importance of sports, is good physical education seriously, formation of physical education learning interest.

Introduced the classroom game, active teaching content. The game method is both a game and the teaching content, teaching students are willing to participate. Using game teaching method should pay attention to some problems: when students must focus on, in order to avoid damage in the event, we will organize some concentration games [7]. Quality training boring, we can adjusted the game method; At the end of the teaching content, might as well use the music accompaniment to relax your 
body - introduce the game into the classroom, not only can stimulate students' learning enthusiasm, can make the underachiever found their own advantages and strengths, but also can adjust students relations and enhance the class cohesion.

Advocates cooperative learning, inspire innovative thinking. Cooperative learning, it is two or more individuals, in order to achieve the common goal and voluntary together, through the mutual coordination and cooperation, to enhance the learning initiative, finally realizes the teaching task of a communication activity [7]. Cooperative learning is given priority to with "student, active learning" as the theoretical basis, the study ideas, innovation "as the core content, with" email is help, encourage competition "for the principle. Cooperative learning is a kind of let the students "competition, in cooperation cooperation in competition", "in the music school, learning fun" in the new teaching mode, which completely accords with the idea of quality education.

\section{Summary}

To sum up, understand the basic situation of the university sports teaching is helpful to analysis and find out existing problems. China University sports education plays a significant role, at the same time can improve the physical quality of college students, in order to increase their ability to adapt to provide good conditions for nature.

\section{References}

[1] J.B. Wei, Depending the reform of sports teaching quality of experimental research, The science and technology consulting herald, 2007, pp.9-13.

[2] Y.W. Zhong, Reflection and countermeasures of physical education curriculum in common colleges and universities, Journal of Chengdu sports institute, 2013, pp.3-7.

[3] Y. Chen andZh. F. Yu, Theory of physical education and man's all-round development, The Harbin sports institute journal, 2014, pp.22-27.

[4] J.Q. Liu, Some thoughts about the implementation of quality education, People's education press, 2006, pp.45-48.

[5] X. M. Wang and J.H. Li, Analyses the concept of health education of colleges and universities sports teaching reform, Journal of Shanxi normal university sports institute, 2008, pp.65-68.

[6] Q.P. Xu and Q.Zh. Li, China's ordinary university sports education reform achievements and deficiencies overview, Hubei sports science and technology, 2007, pp. 41-46.

[7] Y.L. Chun, The ordinary university sports curriculum reform theory and practice,Journal of Jilin institute of sport, 2010, pp.14-18. 